\title{
Can Drug Repurposing be Effective Against Carbapenem-Resistant Acinetobacter baumannii?
}

\author{
Aline Vidal Lacerda Gontijo ${ }^{1}$ Sharlene Lopes Pereira ${ }^{1}$ Herval de Lacerda Bonfante ${ }^{1,2,3}$
}

Received: 22 December 2020 / Accepted: 9 September 2021 / Published online: 14 December 2021

(c) The Author(s), under exclusive licence to Springer Science+Business Media, LLC, part of Springer Nature 2021

\begin{abstract}
Carbapenem-resistant Acinetobacter baumannii has been classified as a top priority for the development of new therapies due to its resistance to most antibiotics. Drug repurposing may be a fast and inexpensive strategy for treating this pathogen. This review aims to critically evaluate repurposed drugs for the treatment of infections caused by carbapenem-resistant $A$. baumannii, correlating their antimicrobial activity with data available for toxicity and side effects. Some drugs have been suggested as promising candidates for repurposing; however, in some cases, high toxicity and low plasma concentrations reduce applicability in clinical practice. The most favorable applicability is offered by fusidic acid and colistin, possibly combined with a third agent, promising to be well tolerated and achieving satisfactory plasma concentrations.
\end{abstract}

\section{Introduction}

\section{Current Outlook: Antimicrobial Resistance is a Real Threat and Few New Drugs Are Being Developed}

Microbial resistance is a serious public health problem [1]. Some bacteria, fungi, viruses, or parasites that were previously susceptible to certain antimicrobial agents have become resistant through various mechanisms. It has been estimated that in the European Union and the European Economic Area, there were 671,689 cases of antibiotic-resistant bacterial infections in 2015 , of which approximately $5 \%$ resulted in deaths [2].

The first public awareness survey on microbial resistance carried out by the World Health Organization (WHO) in February 2017 stated that this problem compromises the

Aline Vidal Lacerda Gontijo

aline.gontijo@gmail.com

1 Department of Pharmacology, Institute of Biological Sciences, Federal University of Juiz de Fora (UFJF), Rua José Lourenço Kelmer, s/n, São Pedro, Juiz de Fora, Minas Gerais 36036-900, Brazil

2 Division of Rheumatology, Hospital Santa Casa de Misericórdia de Juiz de Fora (SCMJF), Juiz de Fora, Minas Gerais, Brazil

3 Department of Internal Medicine, School of Medical Sciences, Health of Juiz de Fora (SUPREMA), Juiz de Fora, Minas Gerais, Brazil treatment of infectious diseases and is considered a serious worldwide threat to public health, thus, receiving a high priority [3]. The WHO's survey published a priority list of resistant pathogens, with 12 bacterial species classified into three priority categories according to their microbial resistance. Three species were considered a critical priority for the research and development of new therapies and included carbapenem-resistant Acinetobacter baumannii. The carbapenem class of antibiotics includes imipenem, meropenem, and doripenem.

A. baumannii is a Gram-negative opportunistic pathogen associated with nosocomial infections such as pneumonia, septicemia, urinary tract infections, endocarditis, meningitis, and wound infections [4]. The pathogenicity of A. baumannii is related to its virulence factors [5]. For example, the porin known as outer membrane protein $\mathrm{A}(\mathrm{OmpA})$ is one of the most studied virulence factors [5]. One of its functions is to bind to the host epithelial cells, reach mitochondria, and induce apoptosis of human cells by releasing proapoptotic molecules such as cytochrome $\mathrm{c}$ and apoptosis-inducing factors. Morris et al. [5] described the functions of several virulence factors in the pathogenesis of A. baumannii infection as well as the host immune responses; further information regarding both issues can be found in the cited work.

Additionally, two other features contributing to the severe infections caused by A. baumannii are (i) the ability to survive in adverse environmental conditions, favoring its persistence and spread in the hospital environment [6], and (ii) the ability to develop resistance to antimicrobial agents. 
In recent years, carbapenem resistance has been reported in A. baumannii [7, 8]. Hospitals in the United States and Europe currently have high rates of carbapenem-resistant A. baumannii [7, 8]. A previous study [8] analyzed the evolution of carbapenem resistance among clinical isolates of A. baumannii obtained from nine tertiary hospitals throughout Greece over 6 years (2010-2015). Imipenem resistance rates were consistently high during this period, ranging from $90.3 \%$ in 2010 to $94.5 \%$ in 2015 , without a significant increase over the years $(P=0.198)$, while meropenem resistance rates increased significantly from $82.6 \%$ in 2010 to $94.8 \%$ in $2015(P=0.006)[8]$.

A report from Emerging Infections Program sites of the Centers for Disease Control Prevention (CDC) covering the period from 2013 to 2017 evaluated the susceptibility of carbapenem-resistant $A$. baumannii to other antibiotics showing that most of the isolates of carbapenem-resistant A. baumannii were consistently resistant to other antibiotics over the years, concluding that treatment options for the infection caused by this pathogen are limited [9].

Colistin and tigecycline are viable therapeutic options for infections caused by carbapenem-resistant strains [10]. However, strains resistant to colistin and tigecycline have also been reported [11]. There is an urgent need for new drugs against this bacterium. The number of approved antimicrobials has decreased in recent decades. One reason is that antimicrobials can quickly become obsolete due to microbial resistance, resulting in a small profit margin for the pharmaceutical industry [12]. As of July 1, 2018, a study [13] identified the following clinical trials on antimicrobials: (i) 30 new antibacterial drugs' chemical entities (NCE) against the WHO priority list of resistant pathogens; (ii) 10 biologicals; (iii) 10 NCEs against Mycobacterium tuberculosis; and (iv) 4 NCEs against Clostridium difficile. Among the 30 NCEs against resistant pathogens, three were active against carbapenem-resistant $A$. baumannii, and five were probably active. Among these eight chemicals, one was in Phase III clinical trials and one was submitted for review by the Food and Drug Administration (FDA) and the European Medicines Agency (EMA) [13].

The number of potential new antibiotics that could help fight microbial resistance including A. baumannii is still very scarce. A recent review identified 407 preclinical studies developing new therapies against bacterial infections, with 135 drugs belonging to a new class, addressing new targets, or providing new mechanisms of action. The authors stated that although the amount of preclinical research is higher compared to the current clinical research trials, more effort and resources are needed to find new effective therapies to overcome the problem of bacterial resistance [14].

\section{Drug Repurposing: Can it be a Solution?}

Drug repurposing has emerged as a potential treatment option for resistant infections [15]. This approach evaluates drugs approved for the treatment of other diseases involving infections. The advantage of drug repurposing is that it quickly increases the arsenal of available drugs for the treatment of infections because some of the drugs' pharmacological properties are already known, saving time, and resources compared to the development of new drugs; drug repurposing has received increasing attention. A recent example of a repurposed drug involves WCK-771 (levonadifloxacin) [16] launched in 1993 by Otsuka for the topical treatment of acne. Parenteral administration, as well as the oral administration of its prodrug (WCK2349 (alalevonadifloxacin)), are being evaluated for the treatment of acute bacterial infections of the skin and skin structure (ABSSSI) as well as for respiratory diseases such as community-acquired bacterial pneumonia (CABP) and hospital-acquired bacterial pneumonia (HABP) [17]. These drugs are active against several pathogens including methicillin-resistant Staphylococcus aureus (MRSA) [16]; they were recently approved in India for ABSSSI based on a completed Phase III trial [18].

Levonadifloxacin is, thus, a successful example of a repurposed drug for the treatment of serious infections. For infections caused by A. baumannii, there is no example of treatment with repurposed drugs. However, some published preclinical studies suggest that repurposed drugs could be promising candidates for the treatment of A. baumannii.

This brings us to the initial question of this section: Drug repurposing: Can it be a solution? From the analysis of previous successful cases, repurposing might be a solution for the resistance of $A$. baumannii, leading to a new treatment for this infection, but the options must be carefully evaluated, as the initially promising drugs may not be viable for clinical practice. Such analysis is the main aim of this study, discussed in the next section.

\section{Critical Evaluation of the Drug Repurposing for the Treatment of Carbapenem-Resistant Acinetobacter baumannii}

Basic research and preclinical studies have undoubtedly contributed to the development of new treatments against infections by examining several drugs that may have activity against a certain agent. However, clinical studies must find viable options with a balance between efficacy, safety, and suitable pharmacokinetic characteristics.

Some preclinical studies have shown promising antibacterial activities of repurposed drugs against 
carbapenem-resistant Acinetobacter baumannii. However, in several of these studies, concentrations at which drugs showed minimal activity were also associated with toxicity.

This review correlates the concentration of the repurposed drugs presenting activity against carbapenemresistant Acinetobacter baumannii with data on toxicity and pharmacokinetics. Such combined analysis is lacking in the literature despite its value in predicting whether a drug might be a feasible therapeutic option in clinical practice; the present survey allows for the classification of repurposed drugs based on their potential clinical viability.

\section{Methodology and Rationale}

The criteria for including drugs in this repurposing review were (i) marketed drugs for human or veterinary use presenting different profiles (lower and higher toxicities, lower and higher plasma concentrations, etc.); (ii) recently reported (since 2015) in vitro and/or in vivo activity against carbapenem-resistant $A$. baumannii; and (iii) antibacterial action in monotherapy or combination with other drugs. The review focused on published studies most cited at the time of writing.

Drugs with high toxicity, such as mitomycin $\mathrm{C}$ and 5-fluorouracil, were included in the present review for a comprehensive discussion. As will be discussed later, mitomycin C could cause bone marrow depression [19]; 5-fluorouracil is associated with gastrointestinal (e.g., diarrhea), hematological (e.g., neutropenia, thrombocytopenia, anemia), and dermal (e.g., hand-foot syndrome) undesirable side effects [20]. Although the toxicity of drugs should be carefully evaluated and toxic drugs should be avoided, this is often not possible. For example, colistin is an old antibiotic that was commercially available in the 1950s and was abandoned because of its nephrotoxicity [21]. However, despite its nephrotoxicity, this antibiotic is currently the last resort option to treat several serious infections including those produced by A. baumannii [22, 23]. In the near future, there may be no treatment against some strains, and repurposed drugs could be a rapid solution to this problem.

The viability of repurposed drugs application in clinical practice was classified as high, intermediate, or low. A drug was classified with high viability if (i) it achieves plasma concentrations higher than the MIC after administration of conventional treatment, and (ii) it is well tolerated and safe for humans at usual doses or its cytotoxicity is low at concentrations higher than the MIC. If only one of these criteria was satisfied, the viability was classified as intermediate, and if none of the criteria were satisfied, the viability was considered low.

\section{Repurposed Drugs for the Treatment of Carbapenem-Resistant Acinetobacter baumannii}

Some studies have shown promising antimicrobial activity against carbapenem-resistant $A$. baumannii.

\section{Apramycin}

One example is apramycin [24, 25], an aminoglycoside used exclusively in animals but in humans [26]. The oral route is used for the treatment of enteric infections in poultry, pigs, and cattle [26]. It is no longer commercially available in the United States; nonetheless, veterinary use is frequent in the European Union [26]. An in vitro study [25] examined the effect of apramycin against $A$. baumannii isolate collection mostly (89\%) non-susceptible to meropenem and/or imipenem carbapenem compounds. The minimum inhibitory concentration (MIC) values required to inhibit $50 \%$ and $90 \%$ of the isolates $\left(\mathrm{MIC}_{50}\right.$ and $\left.\mathrm{MIC}_{90}\right)$ were 8 and $32 \mathrm{mg} / \mathrm{L}$, respectively; these values are at least eightfold lower than those for other aminoglycosides [25].

An in vivo study involving 23 mice highlighted the activity of apramycin against carbapenem-resistant $A$. baumannii. The mice were inoculated with two strains of carbapenemresistant $A$. baumannii and subsequently treated with a single dose of 80 or $500 \mathrm{mg} \mathrm{kg}^{-1}$ subcutaneously. The lowest and highest doses reduced the bacterial load by at least $1-\log _{10}$ (one order of magnitude) and 4- $\log _{10}$ (four orders of magnitude), respectively. Studies in humans should be performed to test this antibacterial effect. A Phase I, randomized, double-blind, placebo-controlled, single ascending dose clinical trial started in September 2019 to evaluate the safety, tolerability, and pharmacokinetics of apramycin after intravenous administration in healthy adults (https:// clinicaltrials.gov/. identifier NCT04105205).

The main side effects of aminoglycosides are ototoxicity and nephrotoxicity [27]. Unlike nephrotoxicity, ototoxicity is irreversible [27]. An advantage of apramycin is its lower ototoxicity compared to other aminoglycosides [28]. An in vitro evaluation [28] of the ototoxicities of different aminoglycosides showed that apramycin presented lower ototoxicity than the aminoglycosides frequently used in humans, with $2 \mathrm{mM}$ of apramycin $(1.080 \mathrm{mg} / \mathrm{L}$, approximately 30 times the $\mathrm{MIC}_{90}$ ) not presenting any toxicity, with cell viability remaining at $100 \%$. Treatment with $5 \mathrm{mM}$ apramycin (2.700 $\mathrm{mg} / \mathrm{L})$ led to a loss of cell viability, but this concentration was approximately 80 times higher than the $\mathrm{MIC}_{90}$. In addition, cochlear explants and in vivo studies indicated lower toxicity of apramycin compared to neomycin and gentamicin (two aminoglycosides clinically used in humans) [28]. The authors mentioned that it would be worth investigating whether the lower ototoxicity of apramycin could be due to its reduced affinity for mechanoelectrical transducer 
(MET) channels, leading to reduced intracellular penetration of apramycin into the cochlear hair cells, thus, decreasing mitochondrial dysfunction [28]. Indeed, Matt et al. [29] showed that apramycin was less ototoxic than other aminoglycosides and presented a reduced ability to inhibit ribosomal mitochondria of eukaryotic cells in comparison to prokaryotic cells; it also generated less reactive oxygen species. A previous study [30] showed that apramycin was less nephrotoxic than gentamicin; however, to the best of our knowledge, there are no further studies on the nephrotoxicity of apramycin.

Another study showed that apramycin maintains its antimicrobial activity against multidrug-resistant (MDR) and extensively drug-resistant (XDR) clinical isolates encoding $\beta$-lactamases such as NDM-1, IMP-1, OXA-23, OXA48, OXA-181, OXA-232, and KPC-2 [31]. Some of these enzymes, such as OXA-23, confer carbapenem resistance to A. baumannii [32]. Oxacilinase OXA-23 belongs to class $\mathrm{D} \beta$-lactamases and has carbapenemase activity [32] that consists of the hydrolysis of carbapenems by the aforementioned enzyme [32]. The acquisition of OXA-23 is the most widespread mechanism of resistance of A. baumannii to carbapenems and the administration of apramycin to treat infections caused by this pathogen could be advantageous.

While offering the above advantages, apramycin seems to be modified by an enzyme known as aminoglycoside 3-N-acetyltransferase-IV (AAC(3)-IV) [31]. Previous studies have identified acetyltransferase types of Acinetobacter spp., such as AAC(3)-I, AAC(3)-II, AAC(3)-III, AAC(6')-I, AAC(6')-II, and AAC(6')-III [33]. However, to the best of our knowledge, AAC (3)-IV has not been reported in A. baumannii. Moreover, the presence of the gene $n p m A$, responsible for encoding $16 \mathrm{~S}$ rRNA m ${ }^{1} \mathrm{~A} 1408$ methyltransferase, can also confer resistance to apramycin [34]; to the best of our knowledge, npmA has not been reported in A. baumannii $[35]$.

\section{Mitomycin C}

Mitomycin $\mathrm{C}$ is another licensed drug with potential activity against multidrug-resistant $A$. baumannii [36]. This drug is a powerful DNA crosslinker used in cancer chemotherapy [37]. In contrast to apramycin, pharmacokinetics, doses, side effects, and administration routes in humans are known, at least for the aforementioned clinical applications.

The $\mathrm{MIC}_{100}$ values for mitomycin $\mathrm{C}$ range between 20 and $30 \mathrm{mg} / \mathrm{L}$ [36]. Additionally, mitomycin C can eradicate persister cells and biofilms of carbapenem-resistant A. baumannii at concentrations between 200 and $600 \mathrm{mg} / \mathrm{L}$ and 250-400 $\mathrm{mg} / \mathrm{L}$, respectively [36]. The authors showed that mitomycin $\mathrm{C}$ administered at 13 to $16 \mathrm{mg} /$ $\mathrm{kg}$ significantly increased the survival of Galleria mellonella larvae previously infected with a lethal amount of carbapenem-resistant $A$. baumannii [36]. The same dose (13-16 mg/kg) of mitomycin C was administered to $G$. mellonella without inoculation of any bacterium and $100 \%$ survived, suggesting that this protective dose from $A$. baumannii infection was not toxic to the larvae, at least after 5 days [36].

However, the clinical doses of mitomycin $\mathrm{C}$ are related to toxicity, with depression of the bone marrow being one of the most frequent side effects [19]. A dose of $50 \mu \mathrm{g} /$ $\mathrm{kg} /$ day (equivalent to approximately $2 \mathrm{mg} / \mathrm{m}^{2}$ ) for 6 days, then every other day, with a total dose between 35 and $50 \mathrm{mg}$, can cause hematologic toxicity, with an incidence of leukopenia and thrombocytopenia of at least $30 \%$ and $50 \%$, respectively [19]. A previous study showed that after a single dose of $60 \mathrm{mg} / \mathrm{m}^{2}$ mitomycin $\mathrm{C}$ by infusion for $60 \mathrm{~min}$, the peak plasma concentration $\left(\mathrm{C}_{\max }\right)$ was approximately $2 \mathrm{mg} / \mathrm{L}$ that is at least 10 times lower than the MIC [38]. It is worth mentioning that this dose was considered high. Another study evaluating the pharmacokinetics of mitomycin $\mathrm{C}$ showed that $\mathrm{C}_{\max }$ varied between 0.4 and $3.2 \mathrm{mg} / \mathrm{L}$ depending on the dose and administration route [39]. Mitomycin $\mathrm{C}$ was administered either as a single agent $\left(10-20 \mathrm{mg} / \mathrm{m}^{2}\right)$ or in a combination regimen $\left(5-10 \mathrm{mg} / \mathrm{m}^{2}\right)$ [39]. Most patients received bolus intravenous administration, but other routes such as bolus intraarterial hepatic infusion and intravenous infusion for 3 and $24 \mathrm{~h}$ were also used [39]. The maximum $\mathrm{C}_{\max }(3.2 \mathrm{mg} / \mathrm{L})$ was still substantially lower than the MIC of mitomycin $\mathrm{C}$ needed to inhibit $A$. baumannii. The steady-state concentrations, after long-term intravenous infusion of mitomycin C $\left(16 \mathrm{mg} / \mathrm{m}^{2}\right)$, were reached after $2-3 \mathrm{~h}$, being $0.15 \mathrm{mg} / \mathrm{L}$ for 3-h, and $0.01 \mathrm{mg} / \mathrm{L}$ for 24-h infusions [39].

The analysis of plasma concentration and MIC is important because it serves as a guide to establish the optimal dose of antibiotics. Each antibiotic has an ideal target concentration. For example, previous studies have shown that $C_{\max }$ for gentamicin must be 7-10 times greater than the MIC to be effective against pathogenic bacteria [40]. An approach that has been used to improve the effectiveness of an antibiotic especially for patients in the intensive care unit is the individualization of the dose of antibiotics through therapeutic drug monitoring (TDM), despite some limitations [41]. This requires knowledge of plasma concentrations and MIC. In general, plasma concentrations should be higher than the MIC, at least during treatment. This is not the case for mitomycin $\mathrm{C}$ against carbapenem-resistant A. baumannii, at least for clinical doses. To achieve plasma concentrations equal to or above the MIC, higher doses should be administered; however, this would likely increase the incidence of toxic effects and render this drug unfeasible to inhibit A. baumannii in clinical practice. 


\section{5-fluorouracil}

In contrast to mitomycin $\mathrm{C}$ that presents a $\mathrm{C}_{\max }$ lower than the MIC after administration of standard doses, a previous study showed that 5-fluorouracil, another anticancer drug, when administered at the conventional dose, provided a $\mathrm{C}_{\max }$ higher than the MIC that is approximately $25 \mathrm{mg} / \mathrm{L}$ [42]. A daily intravenous bolus of $370 \mathrm{mg} / \mathrm{m}^{2} 5$-fluorouracil provided a $\mathrm{C}_{\max }$ of approximately $50 \mathrm{mg} / \mathrm{L}$ [43]. The oral administration of its prodrug, capecitabine, at $1250 \mathrm{mg} / \mathrm{m}^{2}$ (clinical dose), leads to a $\mathrm{C}_{\max }$ of 5 -fluorouracil $(0.22-0.31 \mathrm{mg} / \mathrm{L})$ that is substantially lower than the MIC [44]. However, this MIC value was obtained using only one strain of A. baumannii. As MIC could vary among strains, more clinical isolates need to be tested to confirm this value.

Despite the overall safety of 5-fluorouracil, this drug is toxic in some cases, with toxicities including gastrointestinal (e.g., diarrhea, nausea, vomiting, mucositis/stomatitis, anorexia), hematological (e.g., neutropenia, thrombocytopenia, anemia), and dermal (e.g., hand-foot syndrome) symptoms [20]. A meta-analysis involving 1219 patients with colorectal cancer receiving 5-fluorouracil intravenously (either by bolus or infusion) showed that $31 \%-34 \%$ of the patients had grade 3 to 4 toxicities as defined by the WHO, with $0.5 \%$ of the patients experiencing lethal toxicity [45]. A relationship was found between acute toxicity and 5-fluorouracil plasma concentrations: 2.5 and $3 \mathrm{mg} / \mathrm{L} 5$-fluorouracil doses were correlated with grades 1 and 2 diarrhea and grade 1 hand-foot syndrome, while plasma levels of more than $3 \mathrm{mg} / \mathrm{L}$ were significantly related to grade 3 diarrhea and hand-foot syndrome [46]. Other studies have observed that dose adjustments to obtain an optimal target concentration could reduce toxicity [47]. Nonetheless, this target concentration is between and $2-3 \mathrm{mg} / \mathrm{L}$ that is lower than the MIC [48]. The combination of 5-fluorouracil with azithromycin was effective against carbapenem-resistant $A$. baumannii, reduced the effective concentrations compared to both monotherapies, and should be evaluated further [42], possibly reducing 5-fluorouracil toxicity.

A possible explanation for the severe and potentially lethal toxicity of 5-fluorouracil in some patients is gene polymorphism [49]; there is evidence that a deficiency of dihydropyrimidine dehydrogenase (DPD) increases its risk of toxicity [49]. DPD, encoded by the DPYD gene, is mainly responsible for the metabolism of 5-fluorouracil in the liver, and its deficiency can lead to toxic concentrations of unmetabolized molecules [49]. There are few genetic variants in the $D P Y D$ gene that are known to reduce enzyme function (e.g., $D P Y D * 2 A / c .1905+1 \mathrm{G}>\mathrm{A}$ ) [49]; however, other genetic variants of DPYD could be involved in 5-fluorouracil toxicity since a patient may present toxicity without possessing any of these well-studied polymorphisms [50]. Although there are commercially available tests to detect some genetic biomarkers and predict 5-fluorouracil toxicity, their sensitivity is low [51]. Consequently, this potential toxicity may limit the use of 5-fluorouracil against $\mathrm{A}$. baumannii infection.

5-fluorouracil is also a traditional antifungal administered as flucytosine, a less toxic prodrug [52]. Flucytosine enters the fungus through an enzyme known as cytosine permease, an intracellular fungal enzyme cytosine deaminase, which converts this prodrug into 5-fluorouracil [52]. Certain bacteria such as Pseudomonas aeruginosa and Escherichia coli present cytosine permease and cytosine deaminase [53]. A. baumannii seems to synthesize cytosine permease, but not cytosine deaminase (https://www.ncbi.nlm.nih.gov/genome/ browse/\#!/proteins/403/205578\%7CAcinetobacter\%20bau mannii/), possibly restricting the use of flucytosine for the treatment of this infection.

Table 1 summarizes the main advantages and limitations of the drugs discussed above for the treatment of infections caused by carbapenem-resistant $A$. baumannii. The viability of the application of the repurposed drugs in clinical practice was classified as high, medium, and low, considering the criteria described in the 'Methodology and rationale' section.

\section{Potential of Repurposed-Drug Combinations for the Treatment of Carbapenem-Resistant Acinetobacter baumannii}

In contrast to the treatment of chronic infections, drug combination therapy is less common in the treatment of acute bacterial infections [54]. However, combinations of two antibiotics have been suggested for the treatment of some acute infections, particularly those caused by MDR and XDR isolates [55]. The clinical evaluation of the association of two $\beta$-lactamase inhibitors with other antibiotics is in Phase III for the treatment of infections by carbapenem-resistant $A$. baumannii-calcoaceticus complex [56]. Theoretically, there are some advantages of drug association [55]: (i) it confers a broader spectrum to cover potential pathogens; (ii) there is a possibility of achieving higher bactericidal concentrations at the infection site for at least one antibiotic (due to drug interactions); (iii) it may minimize the emergence of antimicrobial resistance even when heteroresistance is a concern; and (iv) it may offer potentially synergistic interactions between two agents. A synergistic interaction results in the combined activity greater than the sum of the drug activities when used individually [57]. A systematic review showed that the combination of antibiotics guided or confirmed by in vitro synergy testing may reduce the mortality of patients with MDR Gram-negative bacterial infections compared with monotherapy or unguided combination therapy [55]. In addition to the combination of two antibiotics, synergism between traditional antibiotics and FDA-approved drugs has been shown in some studies and has been identified as a 


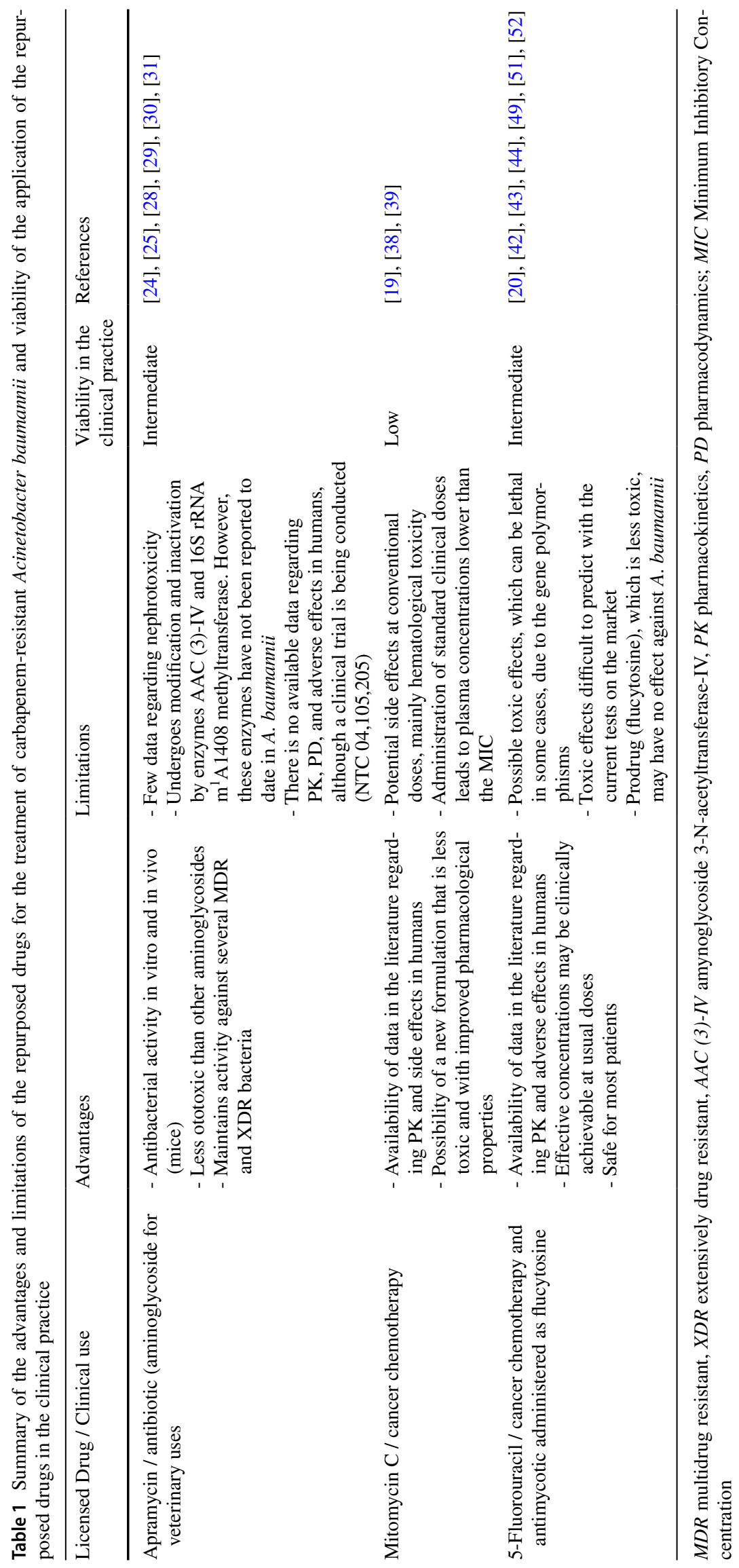


promising therapy for the treatment of carbapenem-resistant A. baumannii [54]. Some of these are discussed below.

\section{Niclosamide-Colistin}

Niclosamide is an antihelminthic drug that has been commercially available in some countries since the 1960s [58]. More recently, it has been proposed for the treatment of other diseases, such as cancer [59].

A synergistic interaction was observed between niclosamide and colistin against carbapenem-resistant A. baumannii. Niclosamide alone did not show any antibacterial activity against $A$. baumannii. However, $0.66 \mathrm{mg} / \mathrm{L}$ of niclosamide in combination with a subinhibitory concentration of colistin $(8 \mathrm{mg} / \mathrm{L})$ reduced the bacterial concentration by almost 6- $\log _{10}$ compared to colistin alone ( $\mathrm{MIC}=256 \mathrm{mg} / \mathrm{L}$ ) [60] . This concentration of $0.66 \mathrm{mg} / \mathrm{L}$ of niclosamide was the minimal concentration that showed synergistic activity with colistin against most strains of carbapenem-resistant A. baumannii.

There are no reports of bacterial resistance to niclosamide in the literature [61], and an in vitro study of multistep resistance with another bacterium (Enterococcus faecium) did not show resistance to niclosamide even after 10 serial passages [62].

Niclosamide is usually administered orally [59]. A favorable characteristic of niclosamide is that the oral dose of $2000 \mathrm{mg}$ once a day was well tolerated and no drug-related toxicities were observed [63]. A Phase I study showed that oral administration of $500 \mathrm{mg}$ three times daily $(1500 \mathrm{mg}$ daily) was safe for humans, in contrast to the administration of $1000 \mathrm{mg}$ three times daily (3000 $\mathrm{mg}$ daily) that was associated with serious side effects [64].

Niclosamide is poorly absorbed by the intestinal mucosa; the administration of $500 \mathrm{mg}$ three times daily resulted in low plasma concentrations, with $\mathrm{C}_{\max }$ ranging from 0.036 to $0.182 \mathrm{mg} / \mathrm{L}$ [64]. The limitation of the cited study is that niclosamide was administered with another anticancer drug (enzalutamide), and the authors did not investigate the potential drug-drug interactions responsible for modifying the plasma concentration [64]. Preliminary results of Phase II clinical trial evaluating niclosamide in patients with metastasized colorectal cancer under standard therapy $(2000 \mathrm{mg}$ once a day by oral route) showed that the median $\mathrm{C}_{\max }$ for five patients was $0.665 \mathrm{mg} / \mathrm{L}$ [65]. This value is close to the concentration of niclosamide that showed synergistic activity with colistin. However, the highest steady-state concentration was $0.598 \mathrm{mg} / \mathrm{L}$, indicating that for most patients, this concentration would be lower than the MIC. The other limitation is that the required colistin concentration for some strains of carbapenem- and colistin-resistant A. baumannii may be as high as $8 \mathrm{mg} / \mathrm{L}$. After intravenous administration, this plasma concentration is clinically achieved only in some patients [66].

\section{Fusidic Acid-Colistin}

Another promising synergic combination to treat carbapenem-resistant $A$. baumannii is colistin with fusidic acid [54, 67]. Fusidic acid has been commercially available since 1962 in Denmark from Leo Laboratories [68]. It is often administered topically, for example, with creams and eye drops [69]. However, systemic administration using oral tablets is also used in some countries [69].

Despite its classification as an antibiotic, fusidic acid is considered a repurposed drug for the treatment of $\mathrm{A}$. baumannii since it is not used for the treatment of infections caused by Gram-negative bacteria. This bacterial group is considered intrinsically resistant because of the inability of fusidic acid to cross the bacterial outer membrane and bind its intracellular target, the elongation factor $\mathrm{G}(\mathrm{EF}-\mathrm{G})$ on the ribosome that inhibits protein synthesis [70]. Although the mechanism of synergism is not known, colistin may interact with LPS in the outer membrane of Gram-negative bacteria that disrupts its integrity, and may increase the permeability to fusidic acid [54].

The literature reports bacterial resistance to fusidic acid due to point mutations in the gene that encodes EF-G (fusA) and/or by the acquisition and expression of genes (such as fus $B$ and fus $C$ ) that have a putative protective effect on EF-G [71]. The association between colistin and fusidic acid seems to limit the development of resistance [54].

The combination is synergistic in the treatment of carbapenem-resistant $A$. baumannii at several concentrations, $1 \mathrm{mg} / \mathrm{L}$ plus $\leq 2 \mathrm{mg} / \mathrm{L} \mathrm{[54]} \mathrm{and} 8 \mathrm{mg} / \mathrm{L}$ plus $\leq 2 \mathrm{mg} / \mathrm{L}$ [72] of acid fusidic and colistin, respectively. Plasma concentrations up to $2 \mathrm{mg} / \mathrm{L}$ of colistin are clinically achievable [66]. Moreover, $8 \mathrm{mg} / \mathrm{L}$ of fusidic acid should be achievable after oral administration $[69,73]$.

A pharmacokinetic-pharmacodynamic modeling study to investigate the in vitro synergy between colistin and fusidic acid against $A$. baumannii showed that although the addition of fusidic acid improved the rate of bacterial killing, this combination was not enough to sustain bacteriostatic activity at clinically achievable concentrations, mainly because of strains' resistance to colistin [67]. The high protein binding of fusidic acid in plasma seems to reduce this interaction [67]. Therefore, Phee et al. highlighted the need for caution in translating the in vitro findings to clinical outcomes [67]. Indeed, only the free fraction of the drug is pharmacologically active at the site of infection, and this fraction is often related to the unbound concentration in plasma [74]. The authors suggested a triple combination with a third agent not yet defined to obtain a clinical effect [67]. 
Within the context of drug repurposing, minocycline could be a viable therapeutic option as a third agent [75]. Minocycline is a broad-spectrum drug belonging to the tetracycline class and was made commercially available in the 1960s, featuring oral and intravenous formulations [75]. Its intravenous formulation was withdrawn in 2005 from the U.S. market. However, it was reintroduced for the treatment of MDR bacteria, particularly carbapenem-resistant A. baumannii [75]. Minocycline is currently used in the clinic against this pathogen, and retrospective studies have shown promising activity for the treatment of this infection; however, to date, there are no randomized, controlled trials to test its effectiveness [75]. Some potential advantages for its use as a third agent in the combination with colistin and fusidic acid are as follows: (i) a mechanism of action different from colistin and fusidic acid since it causes conformational changes to the RNA by binding to the $30 \mathrm{~S}$ ribosomal unit; (ii) previous clinical experience in combination with colistin, without apparent incompatibilities between these drugs; (iii) safety and low cost; and (iv) favorable pharmacokinetic properties including exceptional oral bioavailability. The potential disadvantages could be (i) unsuitability for urinary infections because of minocycline high lipophilicity; (ii) potential mechanism of resistance development to minocycline through efflux; and (iii) possible drug-drug interactions; to the best of our knowledge, there are no data about the association between these three compounds, so possible interactions cannot be discarded.

\section{Polymixin b-Mitotane}

Another potentially effective combination against carbapenem-resistant $A$. baumannii is polymyxin b with mitotane $[76,77]$. Polymyxin b belongs to the same class of colistin (polymyxins) [78]. According to the CLSI guidelines, $A$. baumannii with $\mathrm{MIC} \leq 2 \mathrm{mg} / \mathrm{L}$ is polymyxin b susceptible, while $A$. baumannii with $\mathrm{MIC} \geq 4 \mathrm{mg} / \mathrm{L}$ is polymyxin b resistant. (Clinical and Laboratory Standards Institute 2016). Mitotane, an isomer of the insecticide dichlorodiphenyltrichloroethane, has been used since 1959 for the treatment of adrenocortical carcinoma (ACC), although its mechanism is not completely understood [79]. For most strains of $A$. baumannii, monotherapy with mitotane was not effective [77]. However, the combination of $4 \mathrm{mg} / \mathrm{L}$ of mitotane and $2 \mathrm{mg} / \mathrm{L}$ of polymyxin b showed synergistic activity in some strains of $A$. baumannii resistant to carbapenem and polymyxin $b$, improving bacterial killing and preventing the emergence of resistance in some cases [77]. The possible mechanisms of action are [76] (i) the impairment of energy production (as it affects the citric acid cycle); (ii) the effect of mitotane on RNA/DNA synthesis through the disturbance of the pentose phosphate pathway. The penetration of mitotane through the membrane to reach its intracellular target is usually not feasible, but the activity of polymyxin $b$ on LPS of the outer membrane, in a similar manner as colistin, makes it easier [76]. Plasma concentrations of $2 \mathrm{mg} / \mathrm{L}$ polymyxin b are clinically achievable [78]. Similarly, $4 \mathrm{mg} / \mathrm{L}$ of mitotane after oral administration can be easily achieved [80-82]. However, mitotane accumulates in lipoproteins, and its lipoprotein-free percentage was determined to be approximately $35 \%$ (including protein-bound and free mitotane) [83]. Similarly, a previous study showed that under normoglycemic conditions, a substantial amount of mitotane is bound to high-density lipoprotein (HDL) and albumin, and stated that the free moiety of mitotane is negligible [84]. This low availability of free drug concentration could compromise the activity of mitotane on A. baumannii, as observed previously for fusidic acid [67].

Another disadvantage of mitotane appears to be its side effects [85]. The most common gastrointestinal manifestations appear at the beginning of treatment, regardless of mitotane plasma concentrations [85]. However, these effects can be controlled by clinical interventions, such as dose reduction [85]. Central neurological toxicity (cerebellar symptoms, impaired cognitive performance) is most related to high concentrations of mitotane ( $>20 \mathrm{mg} / \mathrm{L})$; nonetheless, impaired memory or attention-deficit may be observed in some patients even at lower concentrations of mitotane [85]. A retrospective study showed grade 3 toxicity in $44 \%$ of patients receiving an average daily dose of mitotane of $6.3 \mathrm{~g}$ [86]. Another potential problem is that there is significant individual variability in the expected and unexpected effects [85]. D'Avolio et al. suggested that this variability may be due to the CYP2B6 polymorphism that affects mitotane pharmacokinetics [87].

Based on the above discussion, the use of FDA-approved drugs in combination with traditional antibacterial agents against $A$. baumannii has advantages and limitations. Table 2 summarizes such aspects for the reviewed combinations, as well as the viability of the application of these combinations in clinical practice following the previously described criteria.

\section{Conclusions}

Recent interest in A. baumannii is mostly due to its seemingly endless capacity to acquire antibiotic resistance. Antibiotics available to treat $A$. baumannii infections are quite limited; this pathogen could become resistant to all available antibiotics. Also, only a few new drugs are being tested in clinical trials. As we are currently experiencing COVID-19, the impact of intractable infections is enormous, generating both social and economic consequences. There is an urgent need for new therapeutic options to treat A. baumannii. 
Table 2 Summary of the main advantages and limitations of the combination between repurposed drugs and traditional antibiotics for the treatment of carbapenem-resistant Acinetobacter baumannii and viability of the application of the repurposed drugs in the clinical practice

\begin{tabular}{|c|c|c|c|c|}
\hline $\begin{array}{l}\text { Drug combinations (Clinical } \\
\text { use) }\end{array}$ & Advantages & Limitations & $\begin{array}{l}\text { Viability in the } \\
\text { clinical practice }\end{array}$ & References \\
\hline $\begin{array}{l}\text { Niclosamide (antihelminthic } \\
\text { drug) + colistin* }\end{array}$ & $\begin{array}{l}\text { - Low toxicity } \\
\text { - Relatively well tolerated } \\
\text { and safe } \\
\text { - No reports of antibacterial } \\
\text { resistance }\end{array}$ & $\begin{array}{l}\text { - Low bioavailability } \\
\text { - Plasma concentrations may } \\
\text { not be enough after admin- } \\
\text { istration of usual doses }\end{array}$ & Intermediate & [62], [63], [64], [65] \\
\hline $\begin{array}{l}\text { Fusidic acid (antibiotic } \\
\text { on Gram-positive bacte- } \\
\text { ria) + colistin* }\end{array}$ & $\begin{array}{l}\text { - Relatively well tolerated } \\
\text { and safe } \\
\text { - Drug association seems } \\
\text { to limit the appearance of } \\
\text { resistance } \\
\text { - Synergic concentrations } \\
\text { should be clinically achiev- } \\
\text { able }\end{array}$ & $\begin{array}{l}\text { - PK-PD model showed } \\
\text { that this combination is } \\
\text { insufficient for sustained } \\
\text { bacteriostatic activity at } \\
\text { clinically achievable free } \\
\text { concentrations }\end{array}$ & High & [54], [67], [69], [73], [74] \\
\hline $\begin{array}{l}\text { Mitotane (treatment of } \\
\text { ACC) + polymyxin } b^{*}\end{array}$ & $\begin{array}{l}\text { - Synergic concentrations } \\
\text { should be clinically achiev- } \\
\text { able at usual doses }\end{array}$ & $\begin{array}{l}\text { - Free plasma moiety of } \\
\text { mitotane is low } \\
\text { - Potential to cause serious } \\
\text { side effects }\end{array}$ & Intermediate & [67], [80], [81], [82], [84], [85] \\
\hline
\end{tabular}

*Traditional antibiotic; $A A C$ adrenocortical carcinoma, $P K-P D$ pharmacokinetics-pharmacodynamics

The repurposing of FDA-approved drugs can be a quick and less expensive alternative to overcome this resistance threat. However, such repurposing is not straightforward and should be carefully evaluated. Clinical trials with patients are the most effective way to assess the efficacy and safety of these drugs.

In conclusion, the drugs discussed here have potential advantages and disadvantages for the treatment of infections caused by carbapenem-resistant $A$. baumannii. In our opinion, although there is no ideal therapy, the combination of fusidic acid and colistin, probably with a third agent (such as minocycline), seems to be the most promising treatment. Among the options reviewed in this work, it appears to be a well-tolerated drug combination with good plasma concentrations achieved in clinical practice. This has the potential to avoid resistant cases and motivate further studies on the synergistic effect of fusidic acid, colistin, and minocycline combinations.

Acknowledgements The authors would like to thank Editage (https:// www.editage.com) for English language editing.

Author Contributions All authors contributed to the study conception and design. AVLG performed the literature search and data analysis. The first draft of the manuscript was written by AVLG and all authors commented on previous versions of the manuscript. All authors critically revised and approved the final manuscript. All authors agree to be accountable for all aspects of the work in ensuring that questions related to the accuracy or integrity of any part of the work are appropriately investigated and resolved.

Funding This research did not receive any specific grant from funding agencies in the public, commercial, or nonprofit sectors.

\section{Declarations}

Conflict of interest There is no declared conflict of interest.

Ethical Approval The paper does not contain any study on human participants or animals.

\section{References}

1. Hofer U (2019) The cost of antimicrobial resistance. Nat Rev Microbiol 17(1):3-3. https://doi.org/10.1038/s41579-018-0125-x

2. Cassini A, Högberg LD, Plachouras D, Quattrocchi A, Hoxha A, Simonsen GS, Colomb-Cotinat M, Kretzschmar ME, Devleesschauwer B, Cecchini M, Ouakrim DA, Oliveira TC, Struelens MJ, Suetens C, Monnet DL, Strauss R, Mertens K, Struyf T, Catry B, Latour K, Ivanov IN, Dobreva EG, Tambic A, Soprek S, Budimir A, Paphitou N, Žemlicková H, Schytte Olsen S, Wolff Sönksen U, Märtin P, Ivanova M, Lyytikäinen O, Jalava J, Coignard B, Eckmanns T, Abu Sin M, Haller S, Daikos GL, Gikas A, Tsiodras S, Kontopidou F, Tóth Á, Hajdu Á, Guólaugsson Ó, Kristinsson KG, Murchan S, Burns K, Pezzotti P, Gagliotti C, Dumpis U, Liuimiene A, Perrin M, Borg MA, de Greeff SC, Monen JCM, Koek MBG, Elstrøm P, Zabicka D, Deptula A, Hryniewicz W, Caniça M, Nogueira PJ, Fernandes PA, Manageiro V, Popescu GA, Serban RI, Schréterová E, Litvová S, Štefkovicová M, Kolman J, Klavs I, Korošec A, Aracil B, Asensio A, Pérez-Vázquez M, Billström H, Larsson S, Reilly JS, Johnson A, Hopkins S (2019) Attributable deaths and disability-adjusted life-years caused by infections with antibiotic-resistant bacteria in the EU and the European Economic Area in 2015: a population-level modelling analysis. Lancet Infect Dis 19(1):56-66. https://doi. org/10.1016/S1473-3099(18)30605-4

3. Tacconelli E, Magrini N, Kahlmeter G, Singh N (2017) Global priority list of antibiotic-resistant bacteria to guide research, 
discovery, and development of new antibiotics. World Health Organization 27

4. Almasaudi SB (2018) Acinetobacter spp. as nosocomial pathogens: epidemiology and resistance features. Saudi J Biol Sci 25(3):586-596. https://doi.org/10.1016/j.sjbs.2016.02.009

5. Morris FC, Dexter C, Kostoulias X, Uddin MI, Peleg AY (2019) The mechanisms of disease caused by Acinetobacter baumannii. Front Microbiol. https://doi.org/10.3389/fmicb.2019.01601

6. Gallego L (2016) Acinetobacter baumannii: factors involved in its high adaptability to adverse environmental conditions. J Microbiol Exp 3(2):00085

7. Zilberberg MD, Kollef MH, Shorr AF (2016) Secular trends in Acinetobacter baumannii resistance in respiratory and blood stream specimens in the United States, 2003 to 2012: a survey study. J Hosp Med 11(1):21-26

8. Dafopoulou K, Tsakris A, Pournaras S (2018) Changes in antimicrobial resistance of clinical isolates of Acinetobacter baumannii group isolated in Greece, 2010-2015. J Med Microbiol 67(4):496-498

9. Centers for Disease Control Prevention (CDC) (2019) Antibiotic resistance threats in the United States 2019. U.S. Department of Health and Human Services, CDC. Report, Atlanta, GA

10. Liang CA, Lin YC, Lu PL, Chen HC, Chang HL, Sheu CC (2018) Antibiotic strategies and clinical outcomes in critically ill patients with pneumonia caused by carbapenem-resistant Acinetobacter baumannii. Clin Microbiol Infect 24(8):908.e901-908.e907. https://doi.org/10.1016/j.cmi.2017.10.033

11. Şimşek M, Demir C (2020) Determination of colistin and tigecycline resistance profile of acinetobacter baumannii strains from different clinical samples in a territory hospital in Turkey. J Health Sci Med Res. https://doi.org/10.31584/jhsmr.2020727

12. Waluszewski A, Baraldi E, Ciabuschi F (2018) Increase Development and Decrease Use! Innovation Controversies Caused by Antimicrobial Resistance. In: Hoholm Thomas, La Rocca Antonella, Aanestad Margunn (eds) Controversies in Healthcare Innovation. Springer, London, pp 309-339

13. Theuretzbacher U, Gottwalt S, Beyer P, Butler M, Czaplewski L, Lienhardt C, Moja L, Paul M, Paulin S, Rex JH, Silver LL, Spigelman M, Thwaites GE, Paccaud J-P, Harbarth S (2019) Analysis of the clinical antibacterial and antituberculosis pipeline. Lancet Infect Dis 19(2):e40-e50. https://doi.org/10.1016/S1473-3099(18) 30513-9

14. Theuretzbacher U, Outterson K, Engel A, Karlén A (2020) The global preclinical antibacterial pipeline. Nat Rev Microbiol 18:275-285

15. Pushpakom S, Iorio F, Eyers PA, Escott KJ, Hopper S, Wells A, Doig A, Guilliams T, Latimer J, McNamee C, Norris A, Sanseau P, Cavalla D, Pirmohamed M (2019) Drug repurposing: progress, challenges and recommendations. Nat Rev Drug Discov 18(1):4158. https://doi.org/10.1038/nrd.2018.168

16. Appalaraju B, Baveja S, Baliga S, Shenoy S, Bhardwaj R, Kongre V, Dattatraya GS, Dhole T, Verma B, Mukherjee DN, Gupta S, Shanmugam P, Iravane J, Mishra SR, Barman P, Chopra S, Hariharan M, Surpam R, Pratap R, Joshi P, Khande H, Mane A, Jain R, Bhagwat S (2020) In vitro activity of a novel antibacterial agent, levonadifloxacin, against clinical isolates collected in a prospective, multicentre surveillance study in India during 2016-18. J Antimicrob Chemother 75(3):600-608. https://doi.org/10.1093/ $\mathrm{jac} / \mathrm{dkz} 493$

17. Bhagwat SS, Nandanwar M, Kansagara A, Patel A, Takalkar S, Chavan R, Periasamy H, Yeole R, Deshpande PK, Bhavsar S (2019) Levonadifloxacin, a novel broad-spectrum anti-MRSA benzoquinolizine quinolone agent: review of current evidence. Drug Des Dev Ther 13:4351

18. Chavan R, Zope V, Chavan N, Shaikh J, Patil K, Yeole R, Bhagwat S, Patel M (2020) Assessment of in vitro inhibitory effects of novel anti MRSA benzoquinolizine fluoroquinolone WCK 771 (levonadifloxacin) and its metabolite on human liver cytochrome P450 enzymes. Xenobiotica. https://doi.org/10. 1080/00498254.2020.1756007

19. Crooke ST, Bradner WT (1976) Mitomycin C: a review. Cancer Treat Rev 3(3):121-139. https://doi.org/10.1016/S03057372(76)80019-9

20. Brutcher E, Christensen D, Smith MH, Koutlas JB, Sellers JB, Timmons T, Thompson J (2018) 5-Fluorouracil and Capecitabine: Assessment and treatment of uncommon early-onset severe toxicities associated with administration. Clin J Oncol Nurs 22(6):627-634

21. Gontijo AVL, Grégoire N, Lamarche I, Gobin P, Couet W, Marchand S (2014) Biopharmaceutical characterization of nebulized antimicrobial agents in rats: 2 Colistin. Antimicrob Agents Chemother 58(7):3950-3956. https://doi.org/10.1128/ aac.02819-14

22. Ehrmann S, Luyt C-E (2020) Optimizing aerosol delivery of antibiotics in ventilated patients. Curr Opin Infect Dis 33(2):197-204

23. Michalopoulos A, Kasiakou SK, Mastora Z, Rellos K, Kapaskelis AM, Falagas ME (2005) Aerosolized colistin for the treatment of nosocomial pneumonia due to multidrug-resistant Gram-negative bacteria in patients without cystic fibrosis. Crit Care 9(1):R53

24. Kang AD, Smith KP, Berg AH, Truelson KA, Eliopoulos GM, McCoy C, Kirby JE (2018) Efficacy of apramycin against multidrug-resistant Acinetobacter baumannii in the murine neutropenic thigh model. Antimicrob Agents Chemother 62(4):e02585-e2517. https://doi.org/10.1128/aac.02585-17

25. Kang AD, Smith KP, Eliopoulos GM, Berg AH, McCoy C, Kirby JE (2017) In vitro Apramycin Activity against multidrug-resistant Acinetobacter baumannii and Pseudomonas aeruginosa. Diagn Microbiol Infect Dis 88(2):188-191. https://doi.org/10.1016/j. diagmicrobio.2017.03.006

26. van Duijkeren E, Schwarz C, Bouchard D, Catry B, Ca P, Baptiste KE, Moreno MA, Rantala M, Ružauskas M, Sanders P, Teale C, Wester AL, Ignate K, Kunsagi Z, Jukes H (2019) The use of aminoglycosides in animals within the EU: development of resistance in animals and possible impact on human and animal health: a review. J Antimicrob Chemother 74(9):2480-2496. https://doi. org/10.1093/jac/dkz161

27. Germovsek E, Barker CI, Sharland M (2017) What do I need to know about aminoglycoside antibiotics? Arch Dis Child Educ Pract 102(2):89-93

28. Ishikawa M, García-Mateo N, Čusak A, López-Hernández I, Fernández-Martínez M, Müller M, Rüttiger L, Singer W, Löwenheim H, Kosec G, Fujs Š, Martínez-Martínez L, Schimmang T, Petković H, Knipper M, Durán-Alonso MB (2019) Lower ototoxicity and absence of hidden hearing loss point to gentamicin $\mathrm{C} 1 \mathrm{a}$ and apramycin as promising antibiotics for clinical use. Sci Rep 9(1):2410. https://doi.org/10.1038/s41598-019-38634-3

29. Matt T, Ng CL, Lang K, Sha S-H, Akbergenov R, Shcherbakov D, Meyer M, Duscha S, Xie J, Dubbaka SR (2012) Dissociation of antibacterial activity and aminoglycoside ototoxicity in the 4-monosubstituted 2-deoxystreptamine apramycin. Proc Natl Acad Sci 109(27):10984-10989

30. Kostrub CF, Diokno R, Aggen J, Miller G, Judice K, TulkensP. (2009) Quantitative comparison of aminoglycoside nephrotoxicity in rats for effective screening and evaluation of new derivatives, and dosing rationales that minimise toxicity. Paper presented at the 19th European Congress of Clinical Microbiology \& Infectious Diseases (ECCMID), Helsinki, FI,

31. Juhas M, Widlake E, Teo J, Huseby DL, Tyrrell JM, Polikanov YS, Ercan O, Petersson A, Cao S, Aboklaish AF, Rominski A, Crich D, Böttger EC, Walsh TR, Hughes D, Hobbie SN (2019) In vitro activity of apramycin against multidrug-, carbapenem- and aminoglycoside-resistant Enterobacteriaceae and 
Acinetobacter baumannii. J Antimicrob Chemother 74(4):944952. https://doi.org/10.1093/jac/dky546

32. Kaitany K-CJ, Klinger NV, June CM, Ramey ME, Bonomo RA, Powers RA, Leonard DA (2013) Structures of the class D carbapenemases OXA-23 and OXA-146: mechanistic basis of activity against carbapenems, extended-spectrum cephalosporins, and aztreonam. Antimicrob Agents Chemother 57(10):4848-4855

33. Gholami M, Haghshenas M, Moshiri M, Razavi S, Pournajaf A, Irajian G, Heidary M (2017) Frequency of 16S rRNA Methylase and Aminoglycoside-Modifying Enzyme Genes among Clinical Isolates of Acinetobacter baumannii in Iran. Iran J Pathol 12(4):329-338

34. Zhang A, Li Y, Guan Z, Tuo H, Liu D, Yang Y, Xu C, Lei C, Wang $H$ (2018) Characterization of resistance patterns and detection of apramycin resistance genes in Escherichia coli isolated from chicken feces and houseflies after apramycin administration. Frontiers in Microbiology. https://doi.org/10.3389/fmicb.2018.00328

35. Huang J, Ye M, Jia X, Yu F, Wang M (2012) Coexistence of arm $A$ and genes encoding aminoglycoside-modifying enzymes in Acinetobacter baumannii. Afr J Microbiol Res 6:5325-5330

36. Cruz-Muñiz MY, López-Jacome LE, Hernández-Durán M, Franco-Cendejas R, Licona-Limón P, Ramos-Balderas JL, Martinéz-Vázquez M, Belmont-Díaz JA, Wood TK, García-Contreras $\mathrm{R}$ (2017) Repurposing the anticancer drug mitomycin $\mathrm{C}$ for the treatment of persistent Acinetobacter baumannii infections. Int J Antimicrob Agents 49(1):88-92. https://doi.org/10.1016/j.ijant imicag.2016.08.022

37. Leung V, Huo YR, Liauw W, Morris DL (2017) Oxaliplatin versus Mitomycin C for HIPEC in colorectal cancer peritoneal carcinomatosis. Eur J Surg Oncol (EJSO) 43(1):144-149. https://doi.org/ 10.1016/j.ejso.2016.09.015

38. Schilcher RB, Young JD, Ratanatharathorn V, Karanes C, Baker LH (1984) Clinical pharmacokinetics of high-dose mitomycin C. Cancer Chemother Pharmacol 13(3):186-190

39. Den Hartigh J, McVie JG, Van Oort WJ, Pinedo HM (1983) Pharmacokinetics of mitomycin $\mathrm{C}$ in humans. Can Res 43(10):5017-5021

40. Llanos-Paez CC, Hennig S, Staatz CE (2017) Population pharmacokinetic modelling, Monte Carlo simulation and semi-mechanistic pharmacodynamic modelling as tools to personalize gentamicin therapy. J Antimicrob Chemother 72(3):639-667. https:// doi.org/10.1093/jac/dkw461

41. Mouton JW, Muller AE, Canton R, Giske CG, Kahlmeter G, Turnidge J (2018) MIC-based dose adjustment: facts and fables. J Antimicrob Chemother 73(3):564-568. https://doi.org/10.1093/ $\mathrm{jac} / \mathrm{dkx} 427$

42. Cheng Y-S, Sun W, Xu M, Shen M, Khraiwesh M, Sciotti RJ, Zheng W (2019) Repurposing screen identifies unconventional drugs with activity against multidrug resistant Acinetobacter baumannii. Front Cell Infect Microbiol. https://doi.org/10.3389/ fcimb. 2018.00438

43. Bocci G, Danesi R, Di Paolo A, Innocenti F, Allegrini G, Falcone A, Melosi A, Battistoni M, Barsanti G, Conte PF, Del Mario T (2000) Comparative pharmacokinetic analysis of 5-fluorouracil and its major metabolite 5-fluoro-5,6-dihydrouracil after conventional and reduced test dose in cancer patients. Clin Cancer Res 6(8):3032-3037

44. Reigner B, Blesch K, Weidekamm E (2001) Clinical pharmacokinetics of capecitabine. Clin Pharmacokinet 40(2):85-104. https:// doi.org/10.2165/00003088-200140020-00002

45. Lévy E, Piedbois P, Buyse M, Pignon JP, Rougier P, Ryan L, Hansen R, Zee B, Weinerman B, Pater J, Leichman C, Macdonald J, Benedetti J, Lokich J, Fryer J, Brufman G, Isacson R, Laplanche A, Quinaux E, Thirion P (1998) Toxicity of fluorouracil in patients with advanced colorectal cancer: effect of administration schedule and prognostic factors. J Clin Oncol 16(11):3537-3541. https:// doi.org/10.1200/jco.1998.16.11.3537

46. Erick G, Remy D, Jacques J, Yacine M, Jean Luc R, Denis P, Etienne D, Gilles P, Alain M, Michele B-C (2008) Individual fluorouracil dose adjustment based on pharmacokinetic followup compared with conventional dosage: results of a multicenter randomized trial of patients with metastatic colorectal cancer. J Clin Oncol 26(13):2099-2105. https://doi.org/10.1200/jco.2007. 13.3934

47. Patel JN, O'Neil BH, Deal AM, Ibrahim JG, Sherrill GB, Olajide OA, Atluri PM, Inzerillo JJ, Chay CH, McLeod HL (2014) A community-based multicenter trial of pharmacokinetically guided 5-fluorouracil dosing for personalized colorectal cancer therapy. Oncologist 19(9):959

48. Kaldate RR, Haregewoin A, Grier CE, Hamilton SA, McLeod HL (2012) Modeling the 5-fluorouracil area under the curve versus dose relationship to develop a pharmacokinetic dosing algorithm for colorectal cancer patients receiving FOLFOX6. Oncologist 17(3):296

49. Amstutz U, Henricks LM, Offer SM, Barbarino J, Schellens JHM, Swen JJ, Klein TE, McLeod HL, Caudle KE, Diasio RB (2018) Clinical pharmacogenetics implementation consortium (CPIC) guideline for dihydropyrimidine dehydrogenase genotype and fluoropyrimidine dosing: 2017 update. Clin Pharmacol Ther 103(2):210-216

50. Fidai SS, Sharma AE, Johnson DN, Segal JP, Lastra RR (2018) Dihydropyrimidine dehydrogenase deficiency as a cause of fatal 5-Fluorouracil toxicity. Autopsy Case Rep. https://doi.org/10. 4322/acr.2018.049

51. Rosmarin D, Palles C, Church D, Domingo E, Jones A, Johnstone E, Wang H, Love S, Julier P, Scudder C (2014) Genetic markers of toxicity from capecitabine and other fluorouracil-based regimens: investigation in the QUASAR2 study, systematic review, and meta-analysis. J Clin Oncol 32(10):1031

52. Nett JE, Andes DR (2016) Antifungal agents: spectrum of activity, pharmacology, and clinical indications. Infect Dis Clin 30(1):51-83

53. Imperi F, Massai F, Facchini M, Frangipani E, Visaggio D, Leoni L, Bragonzi A, Visca P (2013) Repurposing the antimycotic drug flucytosine for suppression of Pseudomonas aeruginosa pathogenicity. Proc Natl Acad Sci 110(18):7458-7463. https://doi.org/ 10.1073/pnas.1222706110

54. Phee LM, Betts JW, Bharathan B, Wareham DW (2015) Colistin and fusidic acid, a novel potent synergistic combination for treatment of multidrug-resistant Acinetobacter baumannii infections. Antimicrob Agents Chemother 59(8):4544-4550

55. Vardakas KZ, Athanassaki F, Pitiriga V, Falagas ME (2019) Clinical relevance of in vitro synergistic activity of antibiotics for multidrug-resistant Gram-negative infections: A systematic review. J Glob Antimicrob Resist 17:250-259. https://doi.org/10. 1016/j.jgar.2019.01.004

56. Sagan O, Yakubsevitch R, Yanev K, Fomkin R, Stone E, Hines D, O'Donnell J, Miller A, Isaacs R, Srinivasan S (2020) Pharmacokinetics and tolerability of intravenous sulbactam-durlobactam with imipenem-cilastatin in hospitalized adults with complicated urinary tract infections, including acute pyelonephritis. Antimicrob Agents Chemother 64(3):e01506-01519. https://doi.org/10. 1128/aac.01506-19

57. Doern CD (2014) When does 2 plus 2 equal 5? A review of antimicrobial synergy testing. J Clin Microbiol 52(12):4124-4128. https://doi.org/10.1128/jcm.01121-14

58. Pearson RD, Hewlett EL (1985) Niclosamide therapy for tapeworm infections. Ann Intern Med 102(4):550-551

59. Li Y, Li P-K, Roberts MJ, Arend RC, Samant RS, Buchsbaum DJ (2014) Multi-targeted therapy of cancer by niclosamide: a new application for an old drug. Cancer Lett 349(1):8-14 
60. Ayerbe-Algaba R, Gil-Marqués ML, Jiménez-Mejías ME, Sánchez-Encinales V, Parra-Millán R, Pachón-Ibáñez ME, Pachón J, Smani Y (2018) Synergistic activity of niclosamide in combination with colistin against colistin-susceptible and colistin-resistant Acinetobacter baumannii and Klebsiella pneumoniae. Front Cell Infect Microbiol. https://doi.org/10.3389/fcimb.2018.00348

61. Gwisai T, Hollingsworth NR, Cowles S, Tharmalingam N, Mylonakis E, Fuchs BB, Shukla A (2017) Repurposing niclosamide as a versatile antimicrobial surface coating against deviceassociated, hospital-acquired bacterial infections. Biomed Mater 12(4):045010. https://doi.org/10.1088/1748-605x/aa7105

62. Mohammad H, AbdelKhalek A, Abutaleb NS, Seleem MN (2018) Repurposing niclosamide for intestinal decolonization of vancomycin-resistant enterococci. Int J Antimicrob Agents 51(6):897904. https://doi.org/10.1016/j.ijantimicag.2018.02.003

63. Burock S, Daum S, Keilholz U, Neumann K, Walther W, Stein U (2018) Phase II trial to investigate the safety and efficacy of orally applied niclosamide in patients with metachronous or sychronous metastases of a colorectal cancer progressing after therapy: the NIKOLO trial. BMC Cancer 18(1):297. https://doi.org/10.1186/ s12885-018-4197-9

64. Schweizer MT, Haugk K, McKiernan JS, Gulati R, Cheng HH, Maes JL, Dumpit RF, Nelson PS, Montgomery B, McCune JS (2018) A phase I study of niclosamide in combination with enzalutamide in men with castration-resistant prostate cancer. PLoS One. https://doi.org/10.1371/journal.pone.0198389

65. Burock S, Daum S, Tröger H, Kim TD, Krüger S, Rieke DT, Ochsenreither S, Welter K, Herrmann P, Sleegers A, Walther W, Keilholz U, Stein U (2018) Niclosamide a new chemotherapy agent? Pharmacokinetics of the potential anticancer drug in a patient cohort of the NIKOLO trial. J Clin Oncol. https://doi.org/ 10.1200/JCO.2018.36.15_suppl.e14536

66. Couet W, Grégoire N, Marchand S, Mimoz O (2012) Colistin pharmacokinetics: the fog is lifting. Clin Microbiol Infect 18(1):30-39. https://doi.org/10.1111/j.1469-0691.2011.03667.x

67. Phee LM, Kloprogge F, Morris R, Barrett J, Wareham DW, Standing JF (2019) Pharmacokinetic-pharmacodynamic modelling to investigate in vitro synergy between colistin and fusidic acid against MDR Acinetobacter baumannii. J Antimicrob Chemother 74(4):961-969. https://doi.org/10.1093/jac/dky524

68. Godtfredsen WO, Jahnsen S, Lorck H, Roholt K, Tybring L (1962) Fusidic acid: a new antibiotic. Nature 193(4819):987-987

69. Turnidge J (1999) Fusidic acid pharmacology, pharmacokinetics and pharmacodynamics. Int J Antimicrob Agents 12:S23-S34

70. Nikaido H (1996) Multidrug efflux pumps of gram-negative bacteria. J Bacteriol 178(20):5853

71. Castanheira M, Watters AA, Bell JM, Turnidge JD, Jones RN (2010) Fusidic Acid Resistance Rates and Prevalence of Resistance Mechanisms among Staphylococcus spp. Isolated in North America and Australia, 2007-2008. Antimicrob Agents Chemother 54(9):3614-3617. https://doi.org/10.1128/aac.01390-09

72. Bowler SL, Spychala CN, McElheny CL, Mettus RT, Doi Y (2016) In vitro activity of fusidic acid-containing combinations against carbapenem-resistant Acinetobacter baumannii clinical strains. Antimicrob Agents Chemother 60(8):5101-5101. https:// doi.org/10.1128/aac.01124-16

73. Still JG, Clark K, Degenhardt TP, Scott D, Fernandes P, Gutierrez MJ (2011) Pharmacokinetics and safety of single, multiple, and loading doses of fusidic acid in healthy subjects. Clin Infect Dis. https://doi.org/10.1093/cid/cir174

74. Howard ML, Hill JJ, Galluppi GR, McLean MA (2010) Plasma protein binding in drug discovery and development. Comb Chem High Throughput Screening 13(2):170-187

75. Fragkou PC, Poulakou G, Blizou A, Blizou M, Rapti V, Karageorgopoulos DE, Koulenti D, Papadopoulos A, Matthaiou DK, Tsiodras S (2019) The role of minocycline in the treatment of nosocomial infections caused by multidrug, extensively drug and pandrug resistant Acinetobacter baumannii: a systematic review of clinical evidence. Microorganisms 7(6):159

76. Tran TB, Bergen PJ, Creek DJ, Velkov T, Li J (2018) Synergistic killing of polymyxin B in combination with the antineoplastic drug mitotane against polymyxin-susceptible and-resistant Acinetobacter baumannii: a metabolomic study. Front Pharmacol 9:359

77. Tran TB, Wang J, Velkov T, Bergen PJ, Li J (2018) Novel polymyxin combination with antineoplastic mitotane improved the bacterial killing against polymyxin-resistant multidrug-resistant gram-negative pathogens. Front Microbiol 9:721

78. Sandri AM, Landersdorfer CB, Jacob J, Boniatti MM, Dalarosa MG, Falci DR, Behle TF, Bordinhão RC, Wang J, Forrest A, Nation RL, Li J, Zavascki AP (2013) Population pharmacokinetics of intravenous polymyxin $\mathrm{b}$ in critically Ill patients: implications for selection of dosage regimens. Clin Infect Dis 57(4):524-531. https://doi.org/10.1093/cid/cit334

79. Waszut U, Szyszka P, Dworakowska D (2017) Understanding mitotane mode of action. J Physiol Pharmacol 68(1):13-26

80. Hermsen IG, Fassnacht M, Terzolo M, Houterman S, den Hartigh J, Leboulleux S, Daffara F, Berruti A, Chadarevian R, Schlumberger M, Allolio B, Haak HR, Baudin E (2011) Plasma concentrations of $o, p^{\prime} \mathrm{DDD}, \mathrm{o}, \mathrm{p}^{\prime} \mathrm{DDA}$, and $\mathrm{o}, \mathrm{p}^{\prime} \mathrm{DDE}$ as predictors of tumor response to mitotane in adrenocortical carcinoma: results of a retrospective ENS@T multicenter study. J Clin Endocrinol Metab 96(6):1844-1851. https://doi.org/10.1210/jc.2010-2676

81. Megerle F, Herrmann W, Schloetelburg W, Ronchi CL, Pulzer A, Quinkler M, Beuschlein F, Hahner S, Kroiss M, Fassnacht M, German ACCSG (2018) Mitotane monotherapy in patients with advanced adrenocortical carcinoma. J Clin Endocrinol Metab 103(4):1686-1695. https://doi.org/10.1210/jc.2017-02591

82. Terzolo M, Baudin E, Ardito A, Kroiss M, Leboulleux S, Daffara F, Perotti P, Feelders RA, Devries JH, Zaggia B (2013) Mitotane levels predict the outcome of patients with adrenocortical carcinoma treated adjuvantly following radical resection. Eur J Endocrinol 169(3):263-270

83. Hescot S, Seck A, Guerin M, Cockenpot F, Huby T, Broutin S, Young J, Paci A, Baudin E, Lombès M (2015) Lipoprotein-free mitotane exerts high cytotoxic activity in adrenocortical carcinoma. J Clin Endocrinol Metab 100(8):2890-2898. https://doi. org/10.1210/jc.2015-2080

84. Gebhardt DOE, Moolenaar AJ, Van Seters AP, Van Der Velde EA, Leuven JAG (1992) The distribution of $o, p^{\prime}$-DDD (Mitotane) among serum lipoproteins in normo-and hypertriglyceridemia. Cancer Chemother Pharmacol 29(4):331-334

85. Puglisi S, Calabrese A, Basile V, Pia A, Reimondo G, Perotti P, Terzolo M (2020) New perspectives for mitotane treatment of adrenocortical carcinoma. Best Pract Res Clin Endocrinol Metab. https://doi.org/10.1016/j.beem.2020.101415

86. Reidy-Lagunes DL, Lung B, Untch BR, Raj N, Hrabovsky A, Kelly C, Gerst S, Katz S, Kampel L, Chou J, Gopalan A, Saltz LB (2017) Complete responses to mitotane in metastatic adrenocortical carcinoma- a new look at an old drug. Oncologist 22(9):1102-1106. https://doi.org/10.1634/theoncologist. 2016-0459

87. D'Avolio A, De Francia S, Basile V, Cusato J, De Martino F, Pirro E, Piccione F, Ardito A, Zaggia B, Volante M (2013) Influence of the CYP2B6 polymorphism on the pharmacokinetics of mitotane. Pharmacogenet Genomics 23(6):293-300

Publisher's Note Springer Nature remains neutral with regard to jurisdictional claims in published maps and institutional affiliations. 